\title{
INTEGRATING THE USE OF ONLINE SOCIAL NETWORKING SITES IN THE COMMUNICATION STRATEGY OF A COMPANY
}

\author{
Mircea FUCIU*, Luigi DUMITRESCU** \\ *Romanian-German University, Sibiu, Romania, \\ "“"Lucian Blaga" University, Sibiu, Romania \\ mirceafuciu@yahoo.com, dumitresculuigi@yahoo.com
}

\begin{abstract}
The usage of online social networking sites has never been stronger for the individuals and for the companies. This paper is underlining the importance of using the online social networking $(O S N)$ sites in the communication strategy of one's company; it presents the concept and the evolution of this marketing tool. It points out the advantages and disadvantages of using such a platform in a marketing campaign. We are underlining the strengths and weaknesses of this tool, as well as the main tactics and actions that the company must use in order to achieve the desired / maximum result when using such a communication platform in its strategy. At the same time we are presenting several results of a quantitative marketing research about how the OSN sites influence the consumers and the buying behaviour.
\end{abstract}

Keywords: online social networking sites, communication, strategy, marketing, manager

\section{Introduction}

Creating value for the companies using the information and communication technologies has become easier and, at the same time, harder in the last decades. The development of the world wide web of the last two decades has created a new environment for the companies to relate and to communicate with their current and potential customers.

Since the late ' 60 s when DARPA created the first version of the Internet and to the early ' 90 s when the development of the Windows platform and the Internet Explorer or Mosaic browsers were created, they have offered the companies a means to communicate with the consumers. This strong development of the Internet usage has led to the development of new communication strategies for the companies.
This usage of the Internet as a base for the creation and usage of an online communication strategy with the consumers (current and potential) has gained a new environment and, at the same time, a new tool for the companies: online social networks (OSN) or the online networking sites.

Through this paper we intend to present the importance of using OSN and of integrating these platforms in the companies' communication strategy.

\section{How did the online social networks come to be?}

Starting from the idea that the companies must use all the available tools at their disposal in order to target and communicate with their customers, we must be aware of the strengths of the new communication and information 
technologies of the $21^{\text {st }}$ century.

Like stated before, the online social networks (OSN) have become one of the main means of communication of the last decade. But one of the main questions that comes to light is: What are the online social networks?

Starting with their development, the OSN like "MySpace, Facebook, LinkedIn, Pinterest, Twitter, Cyworld, and Bebo and others have attracted millions of users, many of whom have integrated these sites into their daily practices" [2].

Before presenting what the OSN mean, we must state that these concepts are based on the concepts of social networks. According to Online Oxford Dictionaries [19] a social network is a "network of social interactions and personal relationships".

The traditional social networks have been studied for more than 50 years. At the present time these studies are directed towards the interpersonal relations between small groups which are mostly due to the impossibility of collecting large sample data. According to Acatrinei and Nistor [2], social networks are dynamic systems that favour the development of relations between individuals by using a created and shared content.

Starting from these concepts and those presented by other authors [3, 4, 5] and from the new developments in information and communication technology, a new trend has developed: that of social dialogue media (social media) using the online medium.

Beginning with the development level and the dimensions of the social networks, the access to new communication technologies and the strong development of the Internet has led to the strong involvement of hundreds or thousands and even millions of individuals that are willing to connect or interact with other people, to share information with regard to their hobbies needs, desires, etc.

American authors Boyd and Ellison [2] define social networking sites "as web- based services that allow individuals to (1) construct a public or semi-public profile within a bounded system, (2) articulate a list of other users with whom they share a connection, and (3) view and traverse their list of connections and those made by others within the system". Also, according to the Online Oxford Dictionaries "a social network is a dedicated website or other application which enables users to communicate with each other by posting information, comments, messages, images, etc." [19].

Some authors [6] define online social networks as "certain means based on a platform aimed at developing online communities where individuals from around the world can connect with each other for a variety of reasons". Other similar definitions presented by Preece and Maloney Krishmar [7] present online social networks as "individuals who get together for a reason and that are guided by specific policies ... using a software".

As we can see from the above mentioned concepts, the online social networking sites are online platforms that offer the possibility to share and communicate with friends, family, colleagues, etc. about different aspects of one's life. But the changes of the online behaviour of the individuals, the development of the new generation of consumers that use the online environment more and more have created important changes in the way we see and use the OSN sites.

These developments and the evolution of the online social networking sites can be seen over the last decade or more. Online social networking sites have developed from small size curiosities to a global phenomenon that is responsible for a significant fraction of the overall Internet page views and engagements [8].

The evolution of the online social networking sites has varied from author to author, but most of them [2,9] agree that the first social networking site was 
considered "SixDegree.com which was launched in 1997, its name originates from the six degrees of separation concept".

According to Nielsen Online's 2009 research report [20], online social networking and blogging sites "are nowadays the fourth most popular activity on the Internet; this means that more than two-thirds of the global on-line population visit and participate in social networks and blogs. In fact, social media have pulled ahead the e-mail in the rank of the most popular online activities".

The main online social networking sites have evolved greatly form a few sites, and with a few users to several million users and even over 1 billion users for one of them. Between 2002 and 2004, several important online networking sites were launched such as: LinkedIn, Friendster, MySpace, Hi5, Flikr and Orkut. 2005 and 2006 have known an additional increase in the number of OSN sites and even in the field of microblogging (Twitter) and video sharing platforms (YouTube). Also, in 2006, the current online social networking site, Facebook, was opened for the greater public, after being launched in 2004 for the Harvard students and in '05 and '06 was opened to high schools and corporations.

The current development level of Facebook.com is presented on the company's website [19]. According to Facebook "there are 1.59 billion monthly active users as of December 31, 2015; 1.44 billion mobile monthly active users as of December 31, 2015; 1.04 billion daily active users on average for December 2015; 934 million mobile daily active users on average for December 2015."

In Romania, there are currently 8.4 million users of Facebook, which represents a $41.75 \%$ of the population penetration. At the same time, the 8.4 million users represent $87.12 \%$ of the Internet users from Romania.

Starting from these demographics we can see that such a strong penetration among the Internet users can be used in the development of a strong online communication strategy based on OSN sites, but at the same time the companies must understand the advantages and disadvantages of using such a tool in the marketing activities.

\section{Online social networks: advantages and disadvantages}

For a better understanding of the effects of the OSN on the company's marketing activity we have to be aware of the main advantages [10] of this marketing platform/tool: (1) Connectivity all over the world - it doesn't matter where the customer is, he/she can be reached and the organisation can connect with him/her in order to transmit information, offers; (2) Common interests of the users - one can choose to connect with individuals and/or organisations that they have common interests with; (3) Sharing information in real time - using the instant messaging app, the individuals can share information in real time. At the same time, the companies are able to use these features to answer the customers rapidly; (4) Targeted and even personalised advertising campaign - most online social networking sites use the personal information of the users in order to create profiles or to profile the different types of individuals; Said profile can be used by the companies to create a personalised/a better targeted strategy; (5) Increased speed and fast going news cyclethe development of ONS has created a very fast news cycle. Mass media companies use the OSN to stay up to date but also to inform the consumers of the news.

At the same time, the companies must be aware of certain disadvantages of online social networking sites when preparing a social media based advertising campaign [11]: (1) social media takes time and effort - companies must be aware that when they start an online social networks advertising campaign they must award time, they have to be always there to update their page; (2) online contact person must be an 
experienced employee - a knowledgeable employee/employees must handle all the requests, messages of the customers. Such an implication raises the costs of the communication campaigns; (3) on-going work - in order to promote your company or your products you must be permanently connected to the online environment; (4) information is only visible for a short time before newer posts replace it; (5) backlash when offensive or derogatory is posted online, or a negative post is related to your company, this can lead to image or consumer losing their interest in you or your products; (6) fraud or identity theft - the information that the companies or the individuals post on an OSN is visible by all social media users and it can be used by all those interested. (7) wasting time - "social media is the most popular use of the Internet - surpassing email - and smartphones and other mobile devices seem to be the driving force behind this trend since 60 percent of the traffic is from a mobile source". [10]

Taking into consideration what we have said, we should create a proper marketing or a communication strategy based on the OSN sites. At the same time, the today's companies must be aware that the online social networking sites have several important strengths and weaknesses.

\section{Online social networks: strengths and weaknesses}

Among the most important strengths that the online social networking sites have, we, as managers, marketers or companies in general, have to take into account the following $[12,13]$ : (1) OSN reaches a very broad audience; (2) OSN is useful for developing the product; (3) OSN allows monitoring campaigns; (4) OSN promotes help and support. But, these ever growing communication platforms have also certain weaknesses [12, 13]: (1) Bad image spreads as fast, (if not faster) than good image; (2) You/the company have to spend time researching what might work; (3) Fast paced nature of OSN can make reaching large audiences relatively difficult; (4) If you do not have visual-based business/ content it can be hard to find/promote.

Starting from these important elements - advantages, disadvantages, strengths and weakness, we can clearly create a proper communication strategy using online social networking platforms. This is why we must underline several actions that support such a communication strategy.

\section{Online communication strategy of the company based on social networking sites}

Each marketing/communication strategy must be creating the following important steps. These steps [21] are as follows: (1) Statement of purpose/Mission statement - state from the beginning the reasons behind the manner in which you develop the communication strategy. This statement must be concise and it should act as a reference and reminder for those using it in their work; (2) Current company situation - asses your company, identify your strengths, weaknesses, opportunities, threats (SWOT), PEST analysis, competitor analysis; (3) Determine your communication objectives $\quad-\quad$ all communication strategies should closely reflect your overall organisational plan; point out the main specific objectives; (4) Identify target group (stakeholders) - the company must create detailed description of the target group (primary/secondary; internal/external); (5) Create the messages starting from the target group and its types of individuals/companies, the marketing specialist must create a message tailored for each target group; (6) Determine the communication channels - after establishing the message, the company must identify the proper delivery channel in order to maximise the results and to reach the highest number of current and potential customers; (7) Create a work plan and an evaluation one - point out the indicators 
and their achievement level, the budget and the main resources that the companies can use in the implementation process. Also, the company must develop effective evaluation tools.

Creating an effective communication strategy is also dependent on being aware of certain specificities [14, 15] of the online social networking sites: (1) Develop a list of social media sites where you can potentially engage with your stakeholders - LinkedIn, Facebook, Twitter, Google+, Pinterest etc.; (2) Create a digital contact database - identify the online trends, the blogs, websites, the individuals that potential and current customers follow and include them in your communication strategy; (3) Permanently create content always be out there, a post, a message, a photo every single day (even on weekends); (4) Permanently be in contact via social media platforms - respond to comments, even negative ones, reward the fans (when the page reached round number of likes, follows - 500, 1000, 1 million, etc.); (5) develop and strengthen relationships - develop online and offline events (webinars, video-conferences, faceto-face meetings, etc.) in order for the community, the suppliers, the consumers to get to know you; (6) Measure and assess the online campaigns - monetarizing online social networks (likes, views, shares), post engagement assessment, measuring, polling the consumers, etc. (7) Be real communicating using OSN should point out and underline the authenticity; the companies need to be clear about what you want to communicate and commit to expressing the true you in everything you do online; (8) Focus on certain online social networking sites that your consumers visit regularly; (9) Show consistency in the delivery of your message.

Recent research done by the authors and presented at international scientific conferences [16, 17] have shown that the consumer use OSN sites and the internet on a daily basis $(86 \%)$, the average time for a visit online is $30 \mathrm{~min}-3 \mathrm{~h}(57 \%)$; the main pages visited by the Internet users are: online social networking sites (88\%); webmail (82\%); news sites (57\%); encyclopaedia (46\%); company pages (38\%); the main online social networks used by the respondents are (in order): Facebook, YouTube, Google +, LinkedIn, etc.

At the same time, the OSN sites have a strong influence on the consumer behaviour, which was resulted from previous research developed by the authors [18], like: “(1) publicity/advertising; (2) availability of the information; (3) positive or negative experiences with products or services; (4) opinions of friends, colleagues and family; (5) received recommendations; (6) group influences". Also, the research developed by Fuciu et al. [18] points out "the main stages of the decision making process on which the OSN have influences are, in the respondents' opinion, the following: (1) information search; (2) option evaluation; (3) post acquisition behaviour and (4) need recognition".

\section{Conclusions}

As we can see from the above presented sections, the OSN sites are one of the most important communication and information platforms when relating to the consumers. We, as companies, managers or marketers must be aware of the impact of using such a communication tool. At the same time, one must understand its evolution, its strengths, weaknesses, advantages and disadvantages.

The companies should be aware how the internet users, the consumers use online social networking sites, what their behaviour is and how to personalize their communication messages in order to reach and maximise their exposure online and to have the best results possible with the least costs.

We acknowledge that our paper presents on a theoretical level the importance of using online social networking sites in the companies' 
communication strategy, but also, we hope that this article, combined with other presented by the authors will raise awareness on the managers and marketers' side, especially in this ever changing social, economic and online environments, where the consumers buy what they want and what they need.

Using OSN sites in the marketing and communication strategy of a $21 \mathrm{st}$ century organisation has become mandatory and essential for success and profit.

\section{References}

[1] Acatrinei, C., Nistor, F.N., The Romanian perspective upon the social customer and online social networks, Management \& Marketing - challenges for the knowledge society, vol. 7 no. 2, pp. $221-236,2012$;

[2] Boyd, D.M., Ellison, N., B., Social network sites: a definition, history and scholarship, Journal of Computer Mediated Communication, vol.13, (1), 2007 http://jcmc.indiana.edu/vol13 /issue1/boyd.ellison.html.

[3] Cachia, R., Companao, R., Da Costa, O., Grasping the potential of online social networks for foresight, Journal of Technological Forecasting and Social Change, vol. 74, pp. 11791203, 2007.

[4] Garton, L., Haythornthwaite, C., Wellman, B., Studying online social networks, Journal of Computer Mediated Communication, vol. 3, nr. 1, 1997.

[5] Marshall, G., Sociology Dictionary, Ankara, Science and Art Press, (1999), in Gurol, M., Donmus, V., Metaphors created by prospective teachers related to the concept of Social Network, Procedia - Social and Behavioural Sciences, vol. 9, 2010, pp. 1489-1496;

[6] Balas, J. (2006), “The social ties that bind”, Computers in Libraries, Vol. 26 No. 2, pp. 39-41.

[7] Preece, J. and Maloney-Krichmar, D. (2005), "Online communities: design, theory, and practice", available at: http://jcmc.indiana.edu/vol10/issue4/preece.html;

[8] Kumar, R., Novak, J., Tomkins, A., Structure and evolution of online social networks, Proceedings of the $11^{\text {th }}$ ACM International Conference on Knowledge Discovery and Data Mining, pp. $611-617,2006$;

[9] Pallis, G., Zeinalipour-Yatzi, D., Diakaiakos, M.D., Online Social Networks - status and trends, A. Vakali \& L.C. Jain (Eds.): New Directions in Web Data Management 1, SCI 331, pp. 213-234, Springer-Verlag Berlin Heidelberg, 2011.

[10]Claywell, C.R., Advantages and Disadvantages of Social Networking, http://socialnetworking.lovetoknow.com/Advantages and_Disadvantages of Social Net working, accessed on March $16^{\text {th }}, 2016$.

[11]Sandilands, T., Advantages and Disadvantages of Social Media Marketing, http://smallbusiness.chron.com/advantages-disadvantages-social-media-marketing21890.html, accessed on March $16^{\text {th }}, 2016$.

[12]Eades, T., What are the strengths and weaknesses of social media marketing, blogs, rich media, email marketing, SEO, and online advertising?, https://www.quora.com/Whatare-the-strengths-and-weaknesses-of-social-media-marketing-blogs-rich-media-emailmarketing-SEO-and-online-advertising, accessed on March 17 $7^{\text {th }}, 2016$.

[13]Hanlon, A.M., The Strengths and Weaknesses of Different Social Media Channels for B2C, http://www.evonomie.net/2013/07/29/marketing/the-strengths-and-weaknesses-ofdifferent-social-media-channels-for-b2c/, July, 29, 2013, accessed on March 17 ${ }^{\text {th }}, 2016$.

[14]Shin, N., 7 Steps for a Successful Social Media Strategy, http://www.socialmediaexaminer.com/7-steps-for-a-successful-social-media-strategy/, June, 21, 2012, accessed on March 17 ${ }^{\text {th }}, 2016$. 
[15]Arruda, W., Three Elements of an Effective Social Media Strategy, http://www.forbes.com/sites/williamarruda/2013/08/27/three-elements-of-an-effectivesocial-media-strategy/\#40e562087543, Forbes Magazine online, August 27, 2013, accessed on March $17^{\text {th }}, 2016$.

[16]Fuciu, M., Dumitrescu, L., Using online social networking sites for doing business - a marketing research, Annales Universitatis Apulensis Series Oeconomica, 16 (2), pp. 159-170, 2014.

[17] Dumitrescu, L., Orzan G., Fuciu, M., Understanding the online consumer behaviour and the usage of the internet as a business environment - a marketing research, Revista Economică, vol. 67, issue 3, pp. 63-79, 2015.

[18]Fuciu, M., Gorski, H., Dumitrescu, L., Qualitative marketing research on the influences of online social networking sites on consumers, Revista Economică, vol. 66, issue 1, pp. $117-135,2014$.

$[19]^{* * *}$ Online Oxford Dictionaries

http://www.oxforddictionaries.com/definition/english/social-network?q=social+network, accessed on March $16^{\text {th }}, 2016$.

[20]*** Nielson's Online Report, Global faces and networked places - a Nielsen report on social networking's new global footprint, March 2009, http://blog.nielsen.com/nielsenwire/wp-

content/uploads/2009/03/nielsen globalfaces mar09.pdf, accessed on March $16^{\text {th }}, 2016$.

[21]*** Developing a communications strategy, https://knowhownonprofit.org/campaigns /communications/effective-communications-1/communications-strategy, accessed on March $17^{\text {th }}, 2016$. 